\title{
An Investigation of Pediatric Nurses' Oral Care Practices
}

\author{
๑ Betül Yavuz'1, ๑ Gülçin Özalp Gerçeker2, ๑ Merve Gümüş3, ๑ Hatice Bal Yılmaz³ \\ ${ }^{1}$ Kütahya University of Health Sciences, Department of Pediatric Nursing, Kütahya, Turkey \\ ${ }^{2}$ Dokuz Eylül University Faculty of Nursing, Department of Pediatric Nursing, İzmir, Turkey \\ ${ }^{3}$ Ege University Faculty of Nursing, Department of Pediatric Nursing, İzmir, Turkey
}

\section{ABSTRACT}

Aim: Oral care is a standard practice used to reduce ventilator-associated pneumonia in intensive care units and in the treatment of chemotherapy-induced oral mucositis. This research examines the oral care practices of pediatric nurses.

Materials and Methods: This is a descriptive and cross-sectional study. Its sample was composed of 90 nurses working in the pediatric services of a university hospital in western Turkey from March to December 2016. The research data was collected using a sociodemographic data form and the Oral Care Practices Information Form.

Results: Of the nurses, $62.2 \%$ had received oral care education. There were statistical differences in oral diagnosis in terms of clinic, work shift, the making of oral diagnoses before each oral care practice, oral care frequency and the number of patients with impaired oral mucosal integrity $(p<0.05)$.

Conclusion: Nurses need training about oral care that is up to date with the literature to manage oral care practices more effectively.

Keywords: Pediatric nurses, oral care, nursing practices

\section{Introduction}

Children need oral care for strong and healthy tooth development and to reduce the risk of infections (1). Oral care is an important part of daily hygiene and is conducted to clean the mouth, prevent infections and provide a sense of comfort and hygiene $(2,3)$.

Dryness of oral mucosa in children, especially in intubated infants who cannot be fed orally, infections due to bacterial and fungal infections of dry membranes, mucus injuries due to long-term endotracheal intubation and even ulcers may develop (2). One of the most important ways to prevent oral mucositis and thus oral infections is good, regular and consistent oral care. The number of the microorganisms can be reduced by increasing the quality and frequency of oral care, thus delaying oral mucositis and its complications (4). Oral care is a standard practice used to reduce ventilatorassociated pneumonia (VAP) in intensive care units (5) and in the treatment of chemotherapy-induced oral mucositis (6) and it must be conducted by nurses or family members for infants and children who are hospitalized and cannot perform it on their own (3). Nurses have three important roles in the management of mucositis: To diagnose and monitor the oral cavity accurately, to provide the most appropriate oral care for the patients' current conditions and to educate patients $(7,8)$.

\section{Address for Correspondence}

Betül Yavuz, Kutahya University of Health Sciences, Department of Pediatric Nursing, Kütahya, Turkey Phone: +90 5063160845 E-mail: betulyavuz32@gmail.com ORCID: orcid.org/0000-0001-7606-6223 Received: 17.07.2019 Accepted: 12.09 .2019

${ }^{\circ}$ Copyright 2020 by Ege University Faculty of Medicine, Department of Pediatrics and Ege Children's Foundation The Journal of Pediatric Research, published by Galenos Publishing House. 
Using soft bristled toothbrushes to prevent mucositis, training patients and health care providers about health care protocols and using valid scales to evaluate mouth ulcers and oral pain are recommended in the guidelines prepared by the Multinational Association for Supportive Care in Cancer and the International Society for Oral Oncology based on the opinions of experts in the field of chemotherapy and limited evidence regarding basic oral care. Nurses' evaluation of patients' mouths at regular intervals using current scales will help to determine both the presence and degree of mucositis and the required oral care frequency $(7,9)$. The Oral Assessment Guide, the Mucositis Evaluation index of the World Health Organization, the National Cancer Institute Toxicity Criteria, the International Child Mucositis Assessment scale and the Oral Assessment Guide for Children and Young People can be used to evaluate mucositis (4,10-15).

The literature includes studies of nurses' oral diagnoses, using scales for oral diagnosis, determining oral care frequency, and using toothbrushes, suction toothbrushes and sponge swabs as oral care materials (16-22). It has also been reported that the solutions that nurses used for oral care were as follows: Sodium bicarbonate, chlorhexidine, salty water, fluoride toothpaste, nystatin, tap water, hydrogen peroxide and sterile water $(16,18-21,23)$. Some studies have conducted randomized controlled trials with oral care solutions made to prevent VAP. They emphasize that oral care is important for the prevention of VAP (2427). Oral care is both the care practice that pediatric nurses should carry out on sick children most often and the one that is neglected most frequently (28).

The aim of this study is to examine the oral care practices of pediatric nurses.

\section{Material and Methods}

\section{Study Population and Design}

This is a descriptive, cross-sectional study. Its sample was composed of 90 pediatric nurses working in the pediatric services of a university hospital in western Turkey between March 2016 and December 2016. Having worked in a pediatric clinic for at least one month and voluntary participation were the inclusion criteria.

\section{Ethical Considerations}

Before starting the study, permission was obtained from the Ethics Committee of Ege University's Faculty of Nursing (IRB no: 2016-43) and from the health institution where the research was conducted. Those nurses who agreed to participate expressed their consent verbally.

\section{Instruments}

Instruments were created by the researchers based on the literature.

\section{The Sociodemographic Data Form}

The sociodemographic data form consists of 6 questions about the pediatric nurses' age, their work experience, their work experience in the pediatric clinic, the number of the patients given care, their education level, the clinic where they were working at the time and the number of patients with impaired oral mucosal integrity.

\section{The Oral Care Practices Information Form}

The Oral Care Practices Information Form was prepared by the researchers according to the literature. It consists of 24 questions about the pediatric nurses' use of oral diagnostic scales in oral diagnosis, the materials and solutions they use for oral care, percentages of usage and dilution ratios of sodium bicarbonate ampoule, oral care frequency, mouthwash and use of chlorhexidine.

\section{Data Collection}

Theresearch datawascollected using a Sociodemographic Data Form and the Oral Care Practices Information Form in face-to-face interviews with the pediatric nurses. Each form took approximately 15 minutes to complete by the researchers.

\section{Statistical Analysis}

SPSS for Windows 16.0 software was used for statistical analyses. Descriptive statistics (frequency distributions, means, standard deviations, etc.) were used for sociodemographic information. Normal distribution was assessed using the Shapiro-Wilk test. The chi-square and ANOVA tests were used to evaluate the differences between dependent and independent variables. The results were assessed at a 95\% confidence interval and a significance level of $p<0.05$ (29).

\section{Results}

The mean age of the pediatric nurses was $32.44 \pm 7.20$ years, and their mean work experience was $9.24 \pm 7.61$ years. Their mean work experience in pediatric services was $6.65 \pm 6.87$ years, and the mean number of the patients given care was $11.26 \pm 6.01$. Of the pediatric nurses, $82.2 \%$ had bachelor's degrees, $7.8 \%$ had master's-doctoral degrees, $6.7 \%$ were graduates of vocational health schools, and $3.3 \%$ had associate's degrees. Of the pediatric nurses, $44.4 \%$ were working in pediatric services, $18.9 \%$ in pediatric 
oncology-hematology, $15.6 \%$ in pediatric intensive care, $14.4 \%$ in pediatric surgery and $6.7 \%$ in neonatal intensive care (Table I).

\section{Oral Care Practices}

Of the pediatric nurses, $66.7 \%$ read the literature on oral care, and $62.2 \%$ had received education on oral care $(n=56)$. Of the pediatric nurses who had received oral care education, $85.7 \%$ did so at in-service programs $(n=48)$, and $14.3 \%$ did so at congresses or in courses $(n=8)$. Of the nurses, $91.1 \%$ made oral diagnosis before doing oral care, and only $3.8 \%$ used the Oral Assessment Guide for oral diagnosis $(n=3)$ and $52.2 \%$ carried out oral diagnosis before shift changes $(n=47)$.

Of the pediatric nurses, $17.8 \%$ used toothbrushes in oral care, none used suction toothbrushes, all of them used tongue depressors and gauze, and $11.1 \%$ used prepackaged oral care sets. Of them, $57.8 \%$ used mouthwash and $12.2 \%$ used chlorhexidine. Of the pediatric nurses, $20.0 \%$ used nystatin $(n=18), 47.8 \%$ used tantum verde $(n=43), 7.8 \%$ used

\begin{tabular}{|c|c|c|}
\hline $\begin{array}{l}\text { Socio-demographic } \\
\text { Characteristics }\end{array}$ & \multicolumn{2}{|c|}{$M \pm S D($ Min-Max) } \\
\hline Mean age & \multicolumn{2}{|c|}{$32.44 \pm 7.20$ (min: $15, \max : 54)$} \\
\hline Work experience & \multicolumn{2}{|c|}{$\begin{array}{l}9.24 \pm 7.61 \text { years } \\
\text { (min: } 3 \text { months, max: } 32 \text { years) }\end{array}$} \\
\hline $\begin{array}{l}\text { Work experience in } \\
\text { the pediatric clinic }\end{array}$ & \multicolumn{2}{|c|}{$\begin{array}{l}6.65 \pm 6.87 \text { years } \\
\text { (min: } 3 \text { months, max: } 31 \text { years) }\end{array}$} \\
\hline $\begin{array}{l}\text { Number of the } \\
\text { patients given care }\end{array}$ & \multicolumn{2}{|c|}{$\begin{array}{l}11.26 \pm 6.01 \text { patients } \\
\text { (min: } 2, \text { max: } 30)\end{array}$} \\
\hline \multicolumn{2}{|l|}{ Education status } & $\mathrm{n}(\%)$ \\
\hline \multicolumn{2}{|c|}{ Graduate of high school } & $6(6.7)$ \\
\hline \multicolumn{2}{|l|}{ Associate's degree } & $3(3.3)$ \\
\hline \multicolumn{2}{|l|}{ Bachelor's degree } & $74(82.2)$ \\
\hline \multicolumn{2}{|l|}{ Post-graduate degree } & $7(7.8)$ \\
\hline \multicolumn{3}{|l|}{ Units } \\
\hline \multicolumn{2}{|l|}{ Pediatric clinic } & $40(44.4)$ \\
\hline \multicolumn{2}{|c|}{ Pediatric oncology-hematology } & $17(18.9)$ \\
\hline \multicolumn{2}{|c|}{ Pediatric intensive care } & $14(15.6)$ \\
\hline \multicolumn{2}{|l|}{ Pediatric surgery } & $13(14.4)$ \\
\hline \multicolumn{2}{|c|}{ Neonatal intensive care } & $6(6.7)$ \\
\hline \multicolumn{2}{|l|}{ Total } & $90(100.0)$ \\
\hline \multicolumn{3}{|c|}{$\begin{array}{l}\text { M: Mean, SD: Standard deviation, Min: Minimum, Max: Maximum, n: Number } \\
\text { of patients }\end{array}$} \\
\hline
\end{tabular}

pheniramine mouthwash ( $n=7$ ), and 6.7\% used chlorhexidine mouthwash $(n=6)$. For oral care practices with tongue depressors and gauze: $21.1 \%$ used sodium bicarbonate ampoules, $75.6 \%$ used diluted sodium bicarbonate ampoules, 4.4\% used powdered sodium bicarbonate, $20.0 \%$ used saline solution, and $12.2 \%$ used distilled or boiled water (Table II). To dilute sodium bicarbonate ampoules: $35.6 \%$ of the pediatric nurses used a ratio of one-to-one $(n=32), 20.0 \%$ used one glass to one ampoule of sodium bicarbonate $(n=18), 14.4 \%$ used $1 \mathrm{~mL}$ sodium bicarbonate to $9 \mathrm{~mL}$ water ( $n=13), 4.4 \%$ used one to three $(n=4)$, and $1.1 \%$ used $1 \mathrm{~mL}$ sodium bicarbonate to $4 \mathrm{~mL}$ of water $(\mathrm{n}=1)$. Of the pediatric nurses, $3.3 \%$ carried out oral aspiration after oral care.

For oral care frequency, the results were: $2.2 \%$ of the pediatric nurses performed oral care once a day, 26.7\% did so twice a day, $23.3 \%$ did so 3 times a day, $24.5 \%$ did so 4 times a day, and $23.3 \%$ did so when needed.

The number of patients with impaired oral mucosal membrane integrity by clinic were: pediatric oncologyhematology (1.94 \pm 1.43$)$, pediatric clinics $(0.95 \pm 1.10)$, neonatal intensive care unit $(0.66 \pm 1.03)$, pediatric surgery $(0.30 \pm 0.48)$ and pediatric intensive care $(1.07 \pm 1.20)$ (Table III).

Table II. The materials and solutions the pediatric nurses used for oral care

\begin{tabular}{|l|l|l|}
\hline \multirow{2}{*}{$\begin{array}{l}\text { Materials and solutions the nurses } \\
\text { used in oral care }\end{array}$} & Yes & No \\
\cline { 2 - 3 } & $\mathrm{n}(\%)$ & $\mathrm{n}(\%)$ \\
\hline Toothbrush & $16(17.8)$ & $74(82.2)$ \\
\hline Suction toothbrush & & $90(100.0)$ \\
\hline Tongue depressor & $90(100.0)$ & - \\
\hline Gauze & $90(100.0)$ & - \\
\hline Prepackaged oral care set & $10(11.1)$ & $80(88.9)$ \\
\hline Toothpaste & $3(3.3)$ & $87(96.7)$ \\
\hline Mouthwash & $52(57.8)$ & $38(42.2)$ \\
\hline Glutamine & $4(4.4)$ & $86(95.6)$ \\
\hline Chlorhexidine & $11(12.2)$ & $79(87.8)$ \\
\hline Sodium bicarbonate ampoule & $19(21.1)$ & $71(78.9)$ \\
\hline Diluted sodium bicarbonate ampoule & $68(75.6)$ & $22(24.4)$ \\
\hline Powdered sodium bicarbonate & $4(4.4)$ & $86(95.6)$ \\
\hline Saline solution & $18(20.0)$ & $72(80.0)$ \\
\hline Distilled water/boiled water & $11(12.2)$ & $79(87.8)$ \\
\hline n: Number of patients & & \\
\hline
\end{tabular}




\section{Oral Care Practices and Socio-demographic Characteristics}

There were statistically significant differences according to the clinic where the pediatric nurses worked and the

\begin{tabular}{|c|c|}
\hline Clinics & $M \pm S D($ Min-Max) \\
\hline Pediatric oncology-hematology & $1.94 \pm 1.43$ (min: $0, \max : 5)$ \\
\hline Pediatric clinic & $0.95 \pm 1.10$ (min: $0, \max : 4)$ \\
\hline Neonatal intensive care & $0.66 \pm 1.03$ (min: $0, \max : 2)$ \\
\hline Pediatric surgery & $0.30 \pm 0.48(\min : 0, \max : 1)$ \\
\hline Pediatric intensive care & $1.07 \pm 1.20$ (min: $0, \max : 4)$ \\
\hline
\end{tabular}

practice of carrying out an oral diagnosis at each shift change $\left(X^{2}=15.561, p=0.004\right)$, carrying out an oral diagnosis before each oral care practice $\left(X^{2}=10.97, p=0.027\right)$, oral care frequency $\left(X^{2}=51.82, p=0.000\right)$ and the number of patients with impaired oral mucosal integrity $(F=4.32, p=0.003)$ $(p<0.05)$.

There were also statistically significant differences with respect to the clinic where the pediatric nurses worked and the use of tooth brushes $\left(X^{2}=10.74, p=0.030\right)$, mouthwash $\left(X^{2}=38.40, p=0.000\right)$, diluted sodium bicarbonate ampoules $\left(X^{2}=14.30, \quad p=0.006\right)$, powdered sodium bicarbonate $\left(X^{2}=17.97, p=0.001\right)$, saline solution $\left(X^{2}=24.94, p=0.000\right)$ and distilled or boiled water $\left(X^{2}=11.31, p=0.023\right)$. However, there were no statistically significant differences in terms of the clinic where the pediatric nurses worked and the use of toothpaste $\left(X^{2}=1.88, p=0.757\right)$, prepackaged oral care sets $\left(X^{2}=5.74, p=0.219\right)$, chlorhexidine $\left(X^{2}=2.46, p=0.651\right)$ and sodium bicarbonate ampoules $\left(X^{2}=6.67, p=0.154\right)(p>0.05)$.

There were no statistically significant differences in terms of the pediatric nurses' education level and the carrying out of oral diagnosis at shift changes $\left(X^{2}=2.97\right.$, $p=0.395)$, the carrying out of oral diagnosis before each oral practice $\left(X^{2}=4.28, p=0.233\right)$, oral care frequency $\left(X^{2}=10.83\right.$, $p=0.543)$ and number of the patients with impaired oral mucosal integrity $(F=0.67, p=0.572)$.

There were statistically significant differences in terms of having received education about oral care and carrying out oral diagnosis before each shift change $\left(X^{2}=4.28, p=0.038\right)$ and oral care frequency $\left(X^{2}=12.20, p=0.016\right)$. However, education about oral care did not make a statistically significant difference in the practice of making oral diagnosis before each oral care $\left(X^{2}=2.28, p=0.131\right)$.

\section{Discussion}

One of the most basic nursing roles is to provide patients with oral care. The first stage of oral care in pediatric oncology and pediatric hematology clinics is to make oral diagnosis before and after treatment (4). Most of the nurses made oral diagnosis before oral care practice, but few of those who made oral diagnosis used the Oral Assessment Guide for oral diagnosis, and only half of them made oral diagnosis before each shift change. Özveren et al. (16) report that $77.8 \%$ of nurses made oral diagnosis, and Ganz et al. (19) report that $95.0 \%$ did so. Ganz et al. (19) found that $71.0 \%$ of the nurses made oral diagnosis before oral care, and $33.0 \%$ did so at each shift change. Feider et al. (18) and Ganz et al. (19) also found that nurses did not use a Standard Oral Diagnostic scale. However, Southern (6) found that nurses used two different oral assessment guides. Training nurses about the use of scales that are valid for oral diagnosis will Increase scale utilization rates.

The American Dental Association recommends that oral care be started a few days after birth. Infants' gums should be cleaned with a piece of gauze after they are fed to protect their teeth from plaque and bits of food. The infants' mouths should be aspirated after oral care, and cleanliness of the lips and moistness of the oral mucosa should be maintained using a sponge swab dipped into an alcohol and oxygen-free water solution (27). In this study, all the pediatric nurses used tongue depressors and gauze, few used prepackaged oral care sets and toothbrushes, and none used suction toothbrushes. Studies have reported high rates of using sponge swabs $(18,20,21)$, gauze $(17,19)$ and gauze with tongue depressors $(16,20)$. Toothbrush use varied, with low use of suction toothbrushes and high use of suction (18-21). It is thought that the difference between the rates of using oral care materials is related to the institutions and clinics where the nurses worked.

In their oral care practices with tongue depressors and gauze, the nurses mostly used diluted sodium bicarbonate ampoules, sodium bicarbonate ampoules, saline solution, distilled or warm water, chlorhexidine or powdered sodium bicarbonate, in order of prevalence. In addition, more than half of them used mouthwash in oral care practices. The nurses mostly used sodium bicarbonate, chlorhexidine and salty water, in order of prevalence $(16,18-21)$. It is thought that the difference between the rates of using oral care solutions is related to the institutions and clinics where the pediatric nurses worked.

Nurses can determine oral care frequency using scores on an oral assessment guide (12). In this study, the frequencies 
were: 2 times a day (26.7\%), 4 times a day (24.4\%), 3 times a day (23.3\%), when needed (23.3\%) and once a day (2.2\%). Özveren et al. (16) found these frequencies as follows: when needed (37.8\%), 3 times a day (18.4\%), 2 times a day (17.3\%) and once a day (9.2\%). However, Ibrahim et al. (17) found the results to be as follows: 2 times a day (61.0\%), once a day $(27.9 \%)$, more than 3 times a day (5.8\%) and 3 times a day (5.2\%). Feider et al. (18) found that almost all the nurses performed oral care 4 times a day or more. It is thought that oral care frequency can be defined more clearly by making the usage of the 'oral assessment guide' common practice.

\section{Evaluation of Oral Care Practices with Respect to Some Variables}

There was a statistical difference with respect to the clinic where the pediatric nurses worked and making oral diagnosis during their work shifts, making oral diagnosis before each oral care, oral care frequency and number of patients with impaired oral mucosal integrity $(p<0.05)$. Feider et al. (18) reported a statistically significant difference in the frequency of oral care practices by those nurses with work experience of 7.1 years or more. Türk et al. (20) found a statistically significant difference in oral care frequency according to the clinic where the nurses worked.

Although saline solution, sodium bicarbonate and chlorhexidine mouthwashes are most commonly recommended, there is no broad consensus in the literature over which solution should be used in oral care or which solution is more effective (12). There was a statistically significant difference in terms of the clinic where the pediatric nurses worked and the use of toothbrushes, mouthwash, diluted sodium bicarbonate ampoules, powdered sodium bicarbonate, saline solution and distilled or boiled water in oral care practices, but no such difference in their use of toothpaste, prepackaged oral care sets, chlorhexidine and sodium bicarbonate ampoules. Türk et al. (20) reported a statistically significant difference in terms of the clinic where the nurses worked and use of chlorhexidine, sponge swabs, gauze wound around tongue depressors and toothbrushes. In a study of oral care practices at four different hospitals, Özveren et al. (16) reported statistically significant differences between the hospitals in terms of use of swabs, suction toothbrushes, mouthwashes and toothpaste; however, there were no statistically significant differences between the hospitals in terms of use of gauze wound around tongue depressors. They also found a statistically significant difference between the hospitals in terms of use of oral care solutions (sodium bicarbonate, chlorhexidine and distilled water).
There was a statistically significant difference between having received education about oral care and the practice of making oral diagnosis before each shift change and oral care frequency. However, the difference between having received education about oral care and carrying out oral diagnosis before each oral care intervention was not statistically significant. Educating nurses about making diagnosis and determining oral care frequency using valid scales, and also administrative encouragement to do so will be effective.

\section{Conclusion}

With regards to the pediatric nurses who took part in this study:

- All used tongue depressors and gauze in oral care practices as stated in the literature.

- Most of the pediatric nurses conducted oral diagnosis but did not use valid assessment tools to do so or to determine oral care frequency.

- Their levels of education about oral care practices were low.

With regards to the prevalence levels of patients with impaired oral mucosal membrane integrity, the clinics were ranked from high to low as follows: pediatric hematology/ oncology, pediatric intensive care, pediatric clinic, neonatal intensive care and pediatric surgery.

All pediatric nurses should use valid scales for oral diagnosis before oral care practices and to determine oral care frequency. Educational programs based on standardized oral care protocols and evidence-based studies, and quasiexperimental research to increase knowledge about oral care should be organized.

\section{Ethics}

Ethics Committee Approval: Permission was obtained from the Ethics Committee of Ege University's Faculty of Nursing (IRB no: 2016-43) and from the health institution where the research was conducted.

Informed Consent: Those nurses who agreed to participate expressed their consent verbally.

Peer-review: Enternally peer-reviewed.

\section{Authorship Contributions}

Surgical and Medical Practices: B.Y., G.Ö.G., M.G., H.B.Y., Concept: B.Y., G.Ö.G., M.G., H.B.Y., Design: B.Y., G.Ö.G., M.G., H.B.Y., Data Collection or Processing: B.Y., G.Ö.G., M.G., H.B.Y., Analysis or Interpretation: B.Y., G.Ö.G., M.G., H.B.Y., Literature Search: B.Y., G.Ö.G., M.G., H.B.Y., Writing: B.Y., G.Ö.G., M.G., H.B.Y. 
Conflict of Interest: None of the authors had conflict of interest.

Financial Disclosure: The authors declared that this study received no financial support.

\section{References}

1. Thomson, WM, Ayers KMS, Broughton JR. Child oral health inequalities in New Zealand: A background paper to the public health advisory committee. National Health Committee 2003; 30-94.

2. Cimete G, Kuğuoğlu S, Dede Çınar N. Çocuk, hastalık ve hastane ortamı. (Child, disease and hospital environment) In: Conk Z, Başbakkal Z, Bal Yılmaz H, Bolısıık B. (eds.). Pediatri Hemşireliği. (Pediatric Nursing) (1st ed) Ankara, Turkey, Akademisyen Tip Kitabevi 2013; 148-49.

3. Brown TL. Pediatric variations of nursing interventions. In: Hockenberry MJ, Wilson D. (eds). Wong's essentials of pediatric nursing (7th ed) Canada, Mosby\&Elseivier 2009; 701.

4. Dağdemir A. Ağız bakımı (Oral care). In: İthan İ, Kutluk T. (eds) Pediatrik Onkoloji El Kitabı (Pediatric Oncology Hand Book). 1. Baskı (1st ed) Ankara, Güneş Tıp Kitabevleri 2009; 59-68.

5. Johnstone L, Spence D, Koziol-McLain J. Oral hygiene care in the pediatric intensive care unit: Practice recommendations. Pediatric Nursing 2010; 36:85-97.

6. Southern $\mathrm{H}$. Oral care in cancer nursing: Nurses' knowledge and educations. Journalof Advance Nursing 2007; 57:631-8.

7. Keefe DM, Schubert MM, Elting LS, et al. Updated Clinical Practice Guidelines for The Prevention and Treatment of Mucositis. Cancer 2007; 109:820-31.

8. Stone R, Fliedner MC, Smiet, ACM. Management of oral mucositis in patients with cancer. European Journal of Oncology Nursing 2009; 9:24-32

9. Eilers ), Million R. Clinical update:prevention and management of oral mucositis in patients with cancer. Seminars in Oncology Nursing 2011; 27:1-16.

10. Eilers I, Berger A, Petersen M. Development, testing and application of the oral asssesment guide. Oncology Nursing Forum 1988; 15:325-30.

11. Cheng KKF, Molassiotis A, Chang AM, Wai WC, Cheung SS. Evaulation of an oral care protocol intervention of chemotherapy-induced oral mucositis in pediatric cancer patients. Eur J Oncol Nursing 2001; 37:2056-63.

12. Can G. Mukozit. (Mucositis) In: Can G. (ed). Onkoloji Hemşireliğinde Kanıta Dayalı Semptom Yönetimi. (Evidencebased symptom management in oncology nursing) İstanbul, Turkey, 3P Pharma Publication Planning, 2007; 81-96.

13. Tomlinson D, Gibson F, Treister N, et al. Refinement of the Children's International Mucositis Evaluation Scale (ChIMES): child and parent perspectives on understandability, content validity and acceptability. European Journal of Oncology Nursing 2010; 14:29-41.

14. YavuzB, BalYılmazH, KaramanN. Kanserliçocuklardauluslararas çocuk mukozit değerlendirme ölçeği Türkçe formunun geçerlilik güvenilirlik çalışması. [A study of reliabilityand validity for the Turkish version of children's international mucositis evaluation scale for children with cancer] Türk Onkoloji Dergisi 2011; 26:157162.

15. Çiftçioğlu Ş, Efe E. Validity and reliability of oral assessment guide for children and young people receiving chemotherapy. Turk J Oncol 2017; 32:133-40.

16. Özveren $H$, Özden D. Turkish nurses' attitudes and practices regarding oral care. International Journal of Nursing Knowledge 2015: 26:163-169.

17. Ibrahim SM, Mudawi AM, Omer O. Nurses' knowledge, attitude and practice of oral care for intensive care unit patients. Open Journal of Stomatology 2015; 5:179-186.

18. Feider LL, Mitchell P, Bridges E. Oral care practices for orally intubated critically Ill adults. American Journal of Critical Care 2010; 19:175-183.

19. Ganz FDK, Fink NF, Raanan O, et al. ICU nurses' oral-care practices and the current best evidence. Journal of Nursing Scholarship 2009; 41:132-8.

20. Türk G, Kocaçal Güler E, Eşer I, Khorshid L. Oral care practices of intensive care nurses: a descriptive study. International Journal of Nursing Practice 2012; 18:347-53.

21. Chan EY, Hui-Ling NG. Oral care practices among critical care nurses in singapore: a questionnaire survey. Applied Nursing Research, 2012; 25:197-204

22. Lin YS, Chang IC, Chang TH, Lou MF. Critical care nurses' knowledge, attitudes and practices of oral care for patients with oral endotracheal intubation:a questionnaire survey. Journal of Clinical Nursing 2011; 20:3204-14.

23. Yavuz B, Bal Yilmaz H. Investigation of the effects of planned mouth care education on the degree of oral mucositis in pediatric oncology patients. Journal of Pediatric Oncology Nursing 2015; 32:45-57.

24. Kushara DM, Friedlander LT, Peterlini MA, Pedreira ML. Oral care and oropharyngeal and tracheal colonization by Gram-negative pathogens in children. Nursing in Critical Care 2012; 17:115-22.

25. Kushara DM, Peterlini MA, Pedreira ML. Oral care with $0.12 \%$ chlorhexidine for the prevention of ventilator-associated pneumonia in critically ill children: Randomised, controlled and double blind trial. International Journal of Nursing Studies 2012; 49:1354-63.

26. Sebastian MR, Lodha R, Kapil A, Kabra SK. Oral mucosal decontamination with chlorhexidin for the prevention of ventilator-associated pneumonia in children - a randomizedcontrolled trial. Pediatr Crit Care Med 2012; 13:30510.

27. Klompas M, Branson R, Eichenwald EC, et al. Strategies to prevent ventilator-associated pneumonia in acute care hospitals:2014 update. Infect Control Hosp Epidemiol 2014; 35:915-36.

28. Spurr S, Bally ), Ogenchuk M. Integrating oral health into pediatric nursing practice:Caring for kids where they live. Journal for Specialists in Pediatric Nursing 2015; 20:105-14.

29. Büyüköztürk Ş. Sosyal bilimler için veri analizi el kitabı istatistik, araştırma deseni SPSS uygulamaları ve yorum (Data analysis handbook for social sciences statistics, research design SPSS applications comments) (8. Baskı (8th ed.)). Ankara, Turkey: Pegem A Yayıncılık, 2014. 